\title{
José Russo, filósofo y maestro
}

\author{
Miguel Angel Polo Santillán \\ Departamento Académico de Filosofía
}

José Antonio Russo Delgado nació en Chiclayo en 1917, año significativo en el panorama mundial. Como joven inquieto y atento al tiempo que vivió, participó en la política como miembro del APRA, lo que le llevaría a prisión (1941) y luego a destierros $(1944,1948)$. Estudió filosofía en esta casa de estudios y posteriormente empezó su labor docente en colegios tanto en el Perú como luego en México.

Debido al destierro, concluye sus estudios de Filosofía en la Universidad Autónoma de México, donde tendrá distinguidos maestros como el filósofo español José Gaos y el filósofo mexicano Antonio Caso.

En 1946 presenta la tesis para optar el grado de Bachiller en Humanidades, titulada Nietzsche y el problema del conocimiento. Al siguiente año presenta la tesis para optar el grado de Doctor en Humanidades, titulada Moral y vida en Federico Nietzsche. Esta última tesis ganará el Premio Nacional de Fomentó a la Cultura "Javier Prado" en-el mismoaño. También es ese año comienza su labor docente en esta universidad con el curso Introducción a la filosofia hasta que suffe destierro en 1948. Regresara al Perú en 1956.

En este intervalo hay tres eventos importantes en su vida, enseña Filosofía Contemporánea en la Universidad de San Carlos de Guatemala (1949-1953), luego trabaja como funcionario de la ONU en Nueva York (1953-1958) y además quizá en este período comienza su interés por el pensamiento oriental. Conoce la Misión Ramakrishna, una de las principales organizaciones hindúes que salieron de la India y difundieron la filosofía india, especificamente la filosofía vedanta advaita. Es a uno de los monjes de esta Misión que el Dr. Russo invitará luego al Perú a una serie de conferencias. Y otro personaje importante en la vida del Dr. Russo fue J. Krishnamurti, filósofo y educador indio con quien se entrevistó por esa época. El espíritu anarquista y librepensador del educador hindú hicieron que el Dr. Russo se interesase por él. Sabemos que uno de los manuscritos que ha dejado el Dr. Russo es una obra sobre este filósofo indio.

LETRAS (Lima), 94: 49-54,1997. 
Es necesario agregar que quizá por esa influencia adopte en ese período una actitud apartidista, la que permanecerá toda su vida.

Luego del destierro, regresará al Perú (1956) y se reintegra a la docencia en esta universidad donde enseñará los cursos de Introducción a la Filosofía, Metafísica, Ontología, Griego, Filosofía Antigua, Filosofía Moderna, Filosofía Contemporánea y sus respectivos Seminarios. Luego de dedicar 32 años ininterrumpidos, el Dr. Russo se jubila el año 1988. El maestro fallece el 27 de julio de 1997.

Como catedrático, el Dr. Russo fue maestro de varias generaciones y cada generación tiene un recuerdo especial y una opinión particular de él. Mi generación, específicamente mi promoción (1981), conoció a un Dr. Russo que ponía una gran pasión en sus clases, asequible a los alumnos, captando no sólo la calidad intelectual sino también humana de ellos. Pero uno de los rasgos característicos era su personalidad liena de energía, presencia que imponía respeto. Recuerdo un día de los años ' 80 , cuando conversaba con él a unos metros de nosotros dos jóvenes comenzaron a discutir y a golpearse, entonces el Dr. Russo inmediatamente los separó y le dijo a uno de ellos: "Si quieres pegar, pégame a mî". Y esa actitud gandhiana puso perplejo al joven, se quedó si saber qué hacer y tuvo que retirarse. $Y$ es que esa personalidad enérgica y decidida infundía respeto tantoentresus amigos comoentre los que no lo eran.

\section{«Jorge Puccinelli Converso»}

Esa misma personalidad la volví a experimentar cuando "desarmó" a un ladrón. Estábamos conversando en un parque cerca a su anterior casa en San Antonio cuando un joven se acercó con una navaja y nos pidió dinero. El Dr. Russo se paró y dijo con serenidad: “¿Por qué actúas así? Ven, siéntate y conversa con nosotros. ¿Tienes algún problema?". Ese acercamiento humano dejó sin voluntad y sin violencia al joven ladrón quien sin decir nada retrocedió y se fue.

¿Tenía el Dr. Russo una filosofía? Quisiera primero recordar las obras del maestro, luego los pensadores que más leía y finalmente señalar algunas características de su filosofía.

Las obras publicadas por el Dr. Russo son las siguientes:

- Nietzsche, la Moral y la Vida (1948).

- Sobre la Paz y el Hombre (1962). 
- Lecciones de Psicología General (1962).

- El hombre y la pregunta por el ser (1963).

- De filosofía, paz y religión (1985).

- Sócrates, problemas y mensaje (1985).

- El Principio (Vol. I de la Colección Los Presocráticos, 1989).

- Lo que es (Vol. III de la Colección Los Presocráticos, 1992).

Además, existe una serie de artículos publicados entre los que podemos señalar los siguientes: "Comentario a la tercera meditación cartesiana" (1946), "Genealogía e Historia en Vico" (1946), "Sentido Ontológico de la paz" (1951), "Luces de Heráclito el Oscuro" (1958), "Filosofia” (1976).

Conocemos además que el Dr. Russo estaba preparando por lo menos tres obras que completarían la Colección Los Presocráticos: IV Lo Múltiple (Anaxágoras, Empédocles), V Los Atomos (Leucipo, Demócrito), VI Los Hombres (Los Sofistas).

Entre los filósofos que considero influenciaron en el Dr. Russo podemos señalar a Heráclito, Parménide, Sócrates, Cusa, Pascal, Nietzsche, Heidegger y Krishnamurti. De cada uno de ellos asumió reflexivamente líneas de trabajo, con su propio estilo literario. Cualquier libro o artículo que se lea del Dr. Russo, encontrará que por su estilo literafio ino puedeseridentificado corralgún pensador.

\section{"Jorge Puccinelli Converso"}

A partir de lo anterior podemos decir que la filosofía del Dr. Russo tiene por lo menos tres características:

Primero es una forma peculiar de entender la filosofía. Para él la filosofía es un ver, un ver que transforma. Y no es una forma arbitraria de entender la filosofía, porque él la encuentra en los filósofos griego, en especial en los presocráticos. Nos dice el Dr. Russo: "ya Pitágoras y Platón vinculaban el ver y la acción, entendían que el ver de la filosofía lo acompaña como su subproducto una transformación; la del ser que ve: ese ver del conocer verdadero produce un cambio en el ser, diviniza " (Letras, 82/83, p. 10).

Esta forma de entender la filosofía hizo que los últimos 10 años, nuestro maestro volviera la vista a la religión, tanto en lecturas como en prácticas. Las últimas veces que fui a su casa en Roque Bologna, los libros que estaban a la mano (es decir, que estaba leyendo) eran obras de Ramana 
Maharshi (místico hindú de principios de siglo), de Krishnamurti y de Nietzsche. Y es que el Dios sensible al corazón de Pascal (es decir, la religión) no se contrapone sino se complementa con la filosofía. En 1961, el Dr. Russo decía a los estudiantes universitarios: "Al abrir los libros abrid también... los brazos y la conciencia y el corazón... sois el corazón del cerebro, la inteligencia que no sólo entiende sino, porque comprende, siente y sufre con los que sufren más amándolos y haciéndose abogada de ellos y trabaja por la transformación de su suerte" ("Tolstoi, un hombre humanizado", p. 121).

El segundo rasgo característico de su filosofía es su crítica valiente y enérgica al statu quo. Y es que de Nietzsche rescata la propuesta de resaltar la actitud enérgica ante los poderes que opimen la grandeza de la vida humana, pero no asume la voluntad de poder. Recuerdo que la última conversación con el Dr. Russo, él nos decía que deberíamos revisar el concepto de voluntad que ha marcado tanto a Occidente. Desde Latinoamérica, Russo no deja de denunciar las injusticias, aun en sus libros de especialidad.

En su obra Sobre la paz y el hombre escribía: “¡Cuidado con los poderosos que os tientan al conformismo o al odio!", palabras válidas todavía hoy día. Y agregaba: "En lugar de conformismo lucha por la justicia. Y en lugar del odio, fraternidad Respetad, per ser hombre, al que consideréis enemigo si no podéis amarlopAsí la lucharse hace ella misma ya triunfo" (pp. 121-122). Era inevitable para un hombre con la sensibilidad de Russo pronunciarse sobre los atropellos contra la vida humana (recuerdo que él promovió una declaración de protesta contra una matanza, creo que fue la de Uchuraccay).

Y tercer rasgo de su pensamiento era su especial interés en los filósofos griegos, Colocaba una especial pasión al enseñar a Heráclito en sus seminarios. Lamentablemente no pudo ver publicada su obra ya indicada. Su conocimiento de griego y de la literatura especializada hacían de sus clases casi un diálogo con los filósofos antiguos. Y es que él decía que no se debe hacer historia de la filosofía griega sino filosofía griega, es decir, filosofar con los filósofos que se exponen. Quien lea sus obras publicadas en vida (y ojalá pudiésemos decir también las publicadas póstumamente), veremos como el estilo del maestro hace que los pensadores presocráticos sean interesantes. 
Para finalizar, creo necesario añadir que el espíritu del Dr. Russo era un espíritu libre. Libertad, aunque explícitamente no hablaba de ella, era lo que enseñaba su filosofía. Nos enseñaba a no seguir a nadie (por eso, al igual que Sócrates, él no tuvo discípulos, aunque le digamos maestro), iba contra el "sí señor" y es que no hay verdad que sea propiedad de alguien o de unos cuantos. Sólo un sentimiento de libertad radical puede colocarnos ante la presencia de la verdad, pero no una doctrina o ideología.

Termino como quizá le hubiera gustado a mi amigo y maestro Russo, citando a Sócrates: "Ya es tiempo de que nos retiremos de aquí, yo para morir, vosotros para vivir. ¿Quién lleva la mejor parte? Eso no lo sabe nadie salvo Dios" (Apología 41d-42). A-Dios maestro Russo.

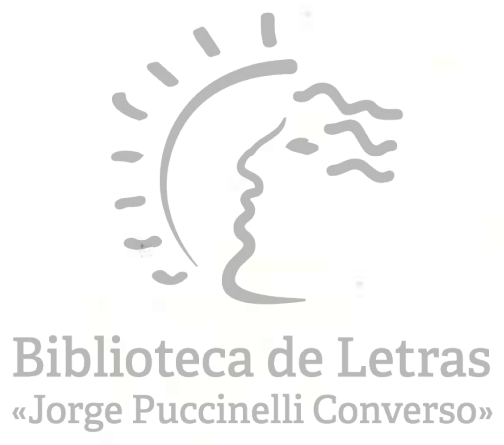

